\title{
The Role of Duration of Diabetes in the Development of Diabetic Retinopathy in Young Diabetic Patients in Bangladesh
}

\author{
SS SUBHAN ${ }^{\mathrm{a}}$, AHS RAHMAN ${ }^{\mathrm{b}}$, A SAYEED $^{\mathrm{c}}$, F HASIN ${ }^{\mathrm{d}}$, R. KARIM ${ }^{\mathrm{e}}$, L ALIf
}

\begin{abstract}
Summary:
The pathogenesis of diabetic retinopathy is still unclear. The relative role of duration of diabetes have been thought to be factor associated with diabetic retinopathy. A total number of 91 diabetic subjects, diabetes diagnosed before the age of 30 years, was recruited from the outpatient department, BIRDEM Hospital. Diabetic subjects recruited were sub grouped according to the duration of diabetes and presence of diabetic retinopathy was
\end{abstract}

\section{Introduction:}

Diabetic retinopathy (DR) is the chronic ocular disorder that develops, at least to some degree, in most of the diabetic cases ${ }^{1}$. DR is highly specific vascular complication occurs in both type 1 and type 2 diabetes. However, it has been shown that retinopathy due to diabetes is strongly associated with duration of diabetes $^{2}$. Prevalence of DR shows wide difference in different geographical areas, and shows ethnic variation. The over all prevalence of DR in Bangladesh has been found to be around $11.1 \%{ }^{3}$. Whereas it's prevalence in some other Asian countries was found between 3\%, lowest in Japan and about $10-32 \%$ in Indonesia ${ }^{4-5}$. If diabetes is

a. Dr. S.S. Subhan, M phil, Assoc. Professor, Biochemistry, NICVD, Dhaka

b. Dr. AHS Rahman, FCPS, Professor, ophthalmology, BIRDEM, Dhaka.

c. Dr. A. Sayeed, FCPS, MS, Assistant Professor, ophthalmology, BIRDEM, Dhaka.

d. Dr. F. Hasin, M Phil, Assistant Professor, Biochemistry, NIKDU, Dhaka.

e. Dr R. Karim, M Phil, Assistant Professor, Biochemistry, HFRCMC \& H, Dhaka.

f. Dr. L Ali, M Phil, PhD, AlProfessor of Biochemistry \& Cocoordinator of Biomedical Research Group, BIRDEM, Dhaka.

Address for Correspondence: Dr. Syeda Shahina Subhan, Associate Professor, National Institute of Cardiovascular Diseases \& Hospital, Phone: 9664338 (Re), 0171600469 (Mob)

Received: 9 March 2005

Accepted: 2 February, 2006 compared. The incidence of retinopathy was highest among the patients with longest duration of diabetes $(p=.004)$ the earlier the age of onset of diabetes the more is the chance of development of diabetic retinopathy. It may be concluded that the duration of diabetes plays a central role in development of diabetic retinopathy in absence of hypertension, hyperlipiedemia and obesity.

(J Bangladesh Coll Phys Surg 2009; 27: 133-138)

diagnosed between the ages of 10 to 30 years, significant retinopathy may arise within 6 years of the disease $^{6}$. With appropriate medical and ophthalmologic care, $>90 \%$ of visual loss resulting from diabetic retinopathy can be prevented ${ }^{1}$.

The clinical course of DR is well understood, but the pathological mechanism of visual loss is yet to be clearly understood ${ }^{7}$. Factors that initiate and promote the development of diabetic retinopathy include duration of diabetes, poor glycolic control, treatment with insulin and associated hypertension and hyperlipidemia ${ }^{8}$. However, other important risk factors so far been associated with DR are age at diagnosis, older patients, puberty, pregnancy, smoking, male sex, leaner patients and populations attending a medical centre as opposed to rural setting ${ }^{9-14}$. Possible causes of pathological basis of anatomical changes in the retina are grouped into three categories: biochemical, homodynamic and endocrine. However, these factors tend to interact in the development of retinopathy 15. A substantial number of diabetic patients in our country belong to younger age group. They do not fit to either of the major two types, type 1 and type 2, of diabetes; however, in the latest classification of diabetes these groups of patients have been classified as type 2 $\mathrm{DM}^{16,17}$. With the availability of this unique group of patients the present study was undertaken to explore the role of clinical characteristics, lipid profile and duration in the development of diabetic retinopathy. 


\section{Materials and method:}

This study was conducted at the Department of Cell and Molecular Biology, Research Division \& Department of Ophthalmology, BIRDEM, during the period of January to June 2002. Total 91 normotensive subjects were included in this case control study who was under 30 years of age at time of diagnosis. They had normal ophthalmologic findings at the time of diagnosis of diabetes mellitus. Pregnant and other albuminuric subjects were excluded. Newly diagnosed group had symptoms of diabetes less than three months. Total patients were divided into 4 groups according to the duration of diabetes.

Group A: twenty two subjects (male $=12$, female $=$ 10) were newly diagnosed patients.

Group B: twenty five subjects (male $=9$, female $=16$ ) had duration of diabetes from one to four years.

Group C: twenty four subjects $($ male $=11$, female $=$ 13) hade duration of diabetes from four years to eight years.

Group D: twenty subjects (male $=10$, female $=10$ ) had duration of diabetes from more than eight years.

Diabetes was diagnosed and classified by the criteria of the report of the Expert Committee on the Diagnosis and Classification of Diabetes Mellitus ${ }^{17}$.

Grading of retinopathy: Was done by two independent trained ophthalmologists, used Airlie House Modification of ETDRS (Early Treatment Diabetic Retinopathy Study) classification ${ }^{3}$. Grading was done in masked fashion so that each grading was independent, and only identification numbers are available to graders. Retinopathy was assessed by:

1. The bright light of a indirect ophthalmoscope, hallogen bulb, direct ophthalmoscope (Kilervista-20).

2. Silt-lamp biomicroscopy with+78D lens.

3. Black and white florescent angiography.

4. Colour fundal photography of central $30^{\circ}$.

Fundus photography was done in all patients and flurescein angiography was done in $25 \%$ of study population.

Anthropometric measurements: The body weight, in kilogram was measured in patients wearing light cloths and height in centimeter was measured by using appropriate scales on bare foot (Detect-Medic, Detect Scales INC, USA). Body mass index of the subjects was calculated as weight in $\mathrm{kg}$ divided by height in square meter.

Measurement of blood pressure: Blood pressure of every subject was measured by the same physician of Research Division, BIRDEM with a sphygmomanometer (Turf Trading Co, Ltd. Tokyo, Japan) in the sitting position.

Biochemical method: All the subjects were explained the test and written consent was obtained from them. Fasting (10-12 hours) blood samples $(5 \mathrm{ml})$ were drawn and serum prepared by centrifugation at 3000 rpm for 10 minutes using refrigerated centrifuge. Serum samples were preserved at $-70^{\circ} \mathrm{C}$ for biochemical analyses, Total cholesterol was measured by enzymatic colorimetric (Cholesterol Oxidase / Peroxides) method (SERA PAK, Bayer USA) ${ }^{18-20}$. Serum triglycerides was measured by enzymatic colorimetric (GPO-PAD) method (SERA PAK, Bayer USA) ${ }^{21}$. Serum High Density Lipoprotein (HDL) was measured by enzymatic colorimetric (Cholesterol Oxidase / Peroxidase) method (SERA PAK, Bayer USA) ${ }^{22}$. The LDL-Cholesterol level in serum was calculated by using Friedewald formula: ${ }^{23}$.

Statistical analysis: All analysis was done using the SPSS (statistical package for social science) package for windows. Experimental values were expressed as mean \pm SD Comparison among groups was done by one way ANOVA with Bonferroni correction. ChiSquare test was also performed for categorical data. To compare results between two groups Student's ttest was performed. Statistical significance was considered to be indicated by a $\mathrm{P}$ value of less than $0.05 \%$ in all cases.

\section{Results:}

The newly diagnosed group (group A) found to have significantly higher age $(25.2 \pm 2.8$ mean \pm SD) at diagnosis compared with group B $(20.4 \pm 4.1)$, C $(17.8 \pm 5.1)$ and $\mathrm{D}(17.7 \pm 4.2)$. BMI of all the four groups did not show any statistical difference among themselves. The group also had similar systolic and diastolic blood pressure (Table-I)

In table II serum total cholesterol triglyceride, HDL Cholesterol and LDL Cholesterol did not show significant difference among different groups. 
Table-I

Clinical characteristic of the study subjects.

\begin{tabular}{lcccc} 
Groups & Age at diagnosis & BMI & SBP & DBP \\
\hline A n=22 (Newly diagnosis) & $25.18 \pm 2.81$ & $21.19 \pm 5.70$ & $109.77 \pm 13.76$ & $74.09 \pm 7.50$ \\
B n=25 (1 years - 4 years) & $20.44 \pm 4.06$ & $19.12 \pm 3.90$ & $104 \pm 10.70$ & $69.80 \pm 8.35$ \\
C n=24 (>4 years -8 years) & $17.79 \pm 5.07$ & $19.18 \pm 2.63$ & $100.63 \pm 10.87$ & $67.08 \pm 7.06$ \\
D n=20 (>8 years) & $17.65 \pm 4.18$ & $19.58 \pm 2.15$ & $108.75 \pm 12.31$ & $71 \pm 7$ \\
F/P & $15.929 / .004$ & $1.436 / .152$ & $2.938 / .152$ & $3.410 / .084$ \\
\hline
\end{tabular}

Results are expressed as mean \pm SD. One way ANOVA with Bonferroni correction was performed. n=numbers of subjects; age at diagnosis, the age at time of diagnosis was first recorded by physician on the patient's chart or on a hospital record; BMI, Body mass index; SBP, Systolic blood pressure; DBP, Diastolic blood pressure.

Table-II

Lipid profile in the study group.

\begin{tabular}{lcccc} 
Groups & T Chol $(\mathrm{mg} / \mathrm{dl})$ & TG $(\mathrm{mg} / \mathrm{dl})$ & HDL-Cho(mg/dl) & LDL-Cho $(\mathrm{Mg} / \mathrm{dl})$ \\
\hline A n=22 (Newly diagnosis) & $163 \pm 36$ & $130 \pm 63$ & $37 \pm 8$ & $100 \pm 35$ \\
B n=25 (1 years -4 years) & $175 \pm 32$ & $139 \pm 35$ & $31 \pm 6$ & $115 \pm 20$ \\
C n=24 (>4 years -8 years) & $158 \pm 23$ & $118 \pm 31$ & $37 \pm 7$ & $97 \pm 23$ \\
D n=20 (>8 years) & $177 \pm 28$ & $133 \pm 43$ & $37 \pm 11$ & $112 \pm 27$ \\
F/P & $1.97 / .48$ & $.939 / .425$ & $2.936 / .152$ & $2.329 / .32$ \\
\hline
\end{tabular}

Results are expressed as mean \pm SD. One way ANOVA with Bonferroni correction was performed. n=numbers of subjects; $\mathrm{T}$ chol, Total Cholesterol; TG, Triglycerides; HDL-cho. High density lipoprotein cholesterol; LDL-cho. Low density lipoprotein cholesterol.

In table III the results showed that in group A $4.55 \%$ had mild retinopathy vs $95.45 \%$ had no change, In group B $20 \%$ had mild retinopathy vs $80 \%$ normal. In group C $12.5 \%$ mild retinopathy vs $87.5 \%$ had no change. In group D 45\% had mild, 10\% moderate, 5\% proliferative type of retinopathy vs $40 \%$ no retinopathy. Diabetic retinopathy had significant association with duration of diabetes $(p=.0004)$ which was showed in table IV.
In table $\mathrm{V}$ it was expressed that there was no significant difference in HDL Cholesterol and LDL Cholesterol. But in DR group total Cholesterol and triglyceride level were significantly higher $(\mathrm{P}=.02)$ and $(\mathrm{P}=.008)$ respectively.

In table VI comparison in detection of retinopathy was expressed. There was no significant difference in detection of retinopathy between Fundus photography and Flurescien Angiography.

Table- III

Ophthalmological finding in the study group. (Grading of Retinopathy)

\begin{tabular}{lcccc} 
Group & $\begin{array}{c}\text { A } \mathrm{n}=22 \\
\text { (Newly diagnosed) }\end{array}$ & $\begin{array}{c}\mathrm{B} \mathrm{n}=25 \\
(1 \text { year }-4 \text { years })\end{array}$ & $\begin{array}{c}\mathrm{C} \mathrm{n}=24 \\
(>4 \text { years }-8 \text { years })\end{array}$ & $\begin{array}{c}\mathrm{D} \mathrm{n}=20 \\
(>8 \text { years })\end{array}$ \\
\hline NDR & $21(95.45 \%)$ & $20(80 \%)$ & $21(87.5 \%)$ & $8(40 \%)$ \\
DR NPDR (mild) & $1(4.55 \%)$ & $5.20 \%)$ & $3(12.5 \%)$ & $9.45 \%)$ \\
DR NPDR (Moderate) & & & $2(10 \%)$ \\
DR PDR & & & $1(5 \%)$ \\
\hline
\end{tabular}

Results are expressed as percentage, $\mathrm{n}=$ number of subjects; NDR, no-diabetic retinopathy; DR, diabetic retinopathy; NPDR (mild), nonproliferative diabetic retinopathy; NPDR (moderate), nonproliferative diabetic retinopathy; (PDR, proliferative diabetic retinopathy. 
Table-IV

Ophthalmological findings in the study group. (Number and percentage of affected person with Diabetic retinopathy)

\begin{tabular}{lcccc}
$\begin{array}{l}\text { Duration of } \\
\text { Diabetes Mellitus }\end{array}$ & $\begin{array}{l}\text { Group }-\mathrm{B} \\
(1 \text { to } 4 \text { years })\end{array}$ & $\begin{array}{c}\text { Group }-\mathrm{C}) \\
(>4 \text { to } 8 \text { years }\end{array}$ & $\begin{array}{c}\text { Group-D } \\
>8 \text { years }\end{array}$ & Total \\
\hline 1 to $>8$ years & $5(20 \%)$ & $3(12.5 \%)$ & $12(60 \%)$ & $20(29.1 \%)$ \\
& $\mathrm{n}=25$ & $\mathrm{n}=24$ & $\mathrm{n}=20$ & $\mathrm{n}=69$ \\
New cases & $1(4.55 \%)$ & $1(4.55 \%)$ & $1(4.55 \%)$ & $1(4.55 \%)$ \\
& $\mathrm{n}=22$ & $\mathrm{n}=22$ & $\mathrm{n}=22$ & $\mathrm{n}=22$ \\
P value & 0.19 & 0.61 & 0.0004 & 0.2 \\
\hline
\end{tabular}

Results are expressed percentage. Chi-Square with Fisher's correction test was performed. n=number of subjects.

Table-V

Biochemical status in NDR (no diabetic retinopathy) and DR (diabetic retinopathy) group.

\begin{tabular}{lcccc} 
Group & T Chol $(\mathrm{mg} / \mathrm{dl})$ & TG $(\mathrm{mg} / \mathrm{dl})$ & HDL-Cho $(\mathrm{mg} / \mathrm{dl})$ & LDL-Cho $(\mathrm{mg} / \mathrm{dl})$ \\
\hline NDR $(\mathrm{n}=70)$ & $164.54 \pm 31.27$ & $124.36 \pm 45.61$ & $35.88 \pm 8.76$ & $103.79 \pm 29.3$ \\
DR $(\mathrm{n}=21)$ & $181.47 \pm 26.89$ & $150.80 \pm 35.27$ & $35.66 \pm 9.50$ & $115.64 \pm 29.2$ \\
t/pvalues & $-2.43 / 02$ & $-2.80 / 008$ & $.09 / .927$ & $-1.63 / .113$ \\
\hline
\end{tabular}

Results are expressed as mean $\pm \mathrm{SD}$. Unpaired student's t-tests was performed. $\mathrm{n}=$ number of subjects; FG, fasting glucose; C-pep: glucose, fasting C-peptide glucose ratio; $\mathrm{HbA}_{1 \mathrm{c}}$, Glycosylated haemoglobin. T chol, Total cholesterol; TG, Triglycerides; HDL-cho. High density lipoprotein cholesterol; LDL-cho. Low density lipoprotein cholesterol. NDR, no diabetic retinopathy; DR, diabetic retinopathy.

\section{Table-VI}

Comparison between Fundus photography and Fluorescien angiography in detection of early retinopathy. (Flurescein leakage negative cases considered as NDR cases.)

\begin{tabular}{lcccc} 
Technique used & DR no $(\%)$ & $\begin{array}{c}\text { DR, NPDR } \\
(\text { mild }) \text { no. }(\%)\end{array}$ & $\begin{array}{c}\text { DR, NPDR } \\
(\text { moderate) no. }(\%)\end{array}$ & $\begin{array}{c}\text { DR, PDR no. } \\
(\%)\end{array}$ \\
\hline Fundus Photography $\mathrm{n}=21$ & $13(62 \%)$ & $10(48 \%)$ & $2(9.52 \%)$ & $1(4.76 \%)$ \\
Fluorescien Angiography $\mathrm{n}=21$ & $9(42.8 \%)$ & $6(26 \%)$ & $2(9.52 \%)$ & $1(4.76 \%)$ \\
P Value & $0.35^{*}$ & $0.31 *$ & $0.56 *$ & $0.66^{*}$ \\
\hline
\end{tabular}

Results were expressed as percentage. Chi-Square test was performed, $n=$ number of subjects; NDR, no diabetic retinopathy; DR, diabetic retinopathy; NPDR (mild), nonproliferative diabetic retinopathy; NPDR (moderate), nonproliferative diabetic retinopathy; PDR, proliferative diabetic retinopathy. $(\{*\}$ Chi-Square with yeats' correction. $\{* *\}$ Chi-Square with Fishers exact.)

\section{Discussion:}

The relation between metabolic control in diabetes and the development and course of duration related micro vascular complications like diabetic retinopathy remains controversial ${ }^{24}$. Even after long years and large number of studies the confusion shows no sign to get cleared. One of the major reasons for such confusions is the complexity of the problem itself.
At cellular level the factors that initiate and promote the development of diabetic retinopathy include duration of diabetes, poor glycaemic control, insulin treated patients and the concomitant presence of hypertension and hyperlipidaemia ${ }^{8}$. It is also influenced by a number of other variables. Although a number of investigators have tried to dissociate those factors with an attempt to explore the 
etiopathogenesis of diabetic retinopathy, most of those have been done by statistical analysis. Moreover, a bulk of those studies was performed on subjects belonging in IDDM and NIDDM group. But studies on a 'third group' 25 without the presence of the complicating variables of diabetic retinopathy would have been ideal to investigate the etiopathogenesis of diabetic retinopathy.

A relatively large number of young lean patients in Bangladesh provide a unique model for such studies. As it can be seen in Table I, 4 groups of diabetic subjects were found BMI matched and they had blood pressure within normal range, Age at onset of diabetes is significantly lower in one group related group to higher incidence of diabetic retinopathy $(60 \%)$. This group has duration of diabetes more than 8 years. Population study in Rochester, Minnesota supported our findings ${ }^{26}$.

Diabetic retinopathy is significantly higher $(60 \%)$ in the subjects who has diabetes for $>8$ years. It is only $4.55 \%$ at the time of diagnosis. So duration of diabetes had a strong positive correlation with the incidence of diabetic retinopathy. This observation is consistent with findings of Frank et $\mathrm{al}^{27}$, Palmberg et al $^{28}$, DCCT data ${ }^{29}$, WESDR data ${ }^{30-31}$. The duration of diabetes had been found repeatedly to be the most important known determinant of the presence of retinopathy.

In DR group, total cholesterol and tryglyceride levels were found higher in comparison to NDR group, but the values of total difference in total cholesterol and triglyceride levels were within normal limit in DR group. But Guereci B et al showed no significant increase of total cholesterol and triglyceride level in diabetic retinopathy except LDL cholesterol which had significant value ${ }^{32}$. It seems that dyslipidemia may also be related to DR, but causal role of it in this pathologic condition in yet to be established.

Color photography and fluorescien a angiography are the two advanced techniques used to confirm diabetic retinopathy. Each modality is more sensitive in detecting early retinopathy than a clinical examination ${ }^{33}$. Palmberg et al 28 found fundus photograph superior to fluorescien angiography but Frank et al ${ }^{27}$ has found the reverse. In DCCT, each method was about equal to the other, DCCT also suggested that, when used in conjunction with color photography, angiography allows a modest increase in sensitivity to the earliest signs of retinopathy, potentially useful in some research applications, although not of demonstrated value in patient management ${ }^{34}$. Airlie house modification of ETDRS classification ${ }^{3}$ uses fundus photography as the standard technique for diagnosis. In the present study fluorescien angiography, similar to DCCT finding, seems to have same sensitivity in diagnosing diabetic retinopathy.

\section{Conclusion:}

It was evident from the study that duration of diabetes plays a central role in the development of diabetic retinopathy. A sudden increase in the prevalence of diabetic retinopathy seems to occur as around 8 years. The incidence of retinopathy was highest among the patients with age of onset of diabetes was lowest. This study showed no relation of diabetic retinopathy with dyslipidemia and hypertension. No discrepancy was seen between the outcome of fundus photography and fluorescien angiography; it remains to be decided which one is preferable. Fundus photography is less costly, least hazardous, can be done in both eye in one sitting, But flurescien angiography is very costly, hazardous (as dye introduced) and patient has to come twice for both eye. So to make a comparison between these two advanced techniques, a substantial number of patients from all grades of diabetic retinopathy would have to take to explore the issue.

Similar studies in adult onset diabetic patients, first degree relatives of diabetic patients, in lean IGT subjects and children in both diabetic patients may also help in deeper understanding of the path physiological basis of diabetic retinopathy.

\section{References:}

1. Aiello LP, Gardener TW, King GL, Blankenship G. Diabetic Retinopathy. Diabetes Care 1998:21(1) : 143-156.

2. Position statement. American Diabetic Association, Diabetic Retinopathy Diabetic Care 1998:21(1) 157-159.

3. Rahman AHS, Ali H. Epidemiology and lesions of Diabetic Retinopathy. In: Rahman AHJ. A H editors, Diabetic Retinopathy and its management, first edition, Diabetic Association of Bangladesh 1998; 32:3-15.

4. Chee JS. and Thai AC. Proceeding of the 7th Congress of the ASIAN Federation of Endocrine Societies 1993; S64:58. 
5. Simons D. Williams SRR, and Powel MJ. Prevalence of diabetes in a predominantly Asian community preliminary finding of the Coventry Diabetes Study Br Med J 1989; 208:18-21.

6. Klein R, Lkein BEK, Moss Se and Cruickshanks KJ. The Wisconsin epidemiologic study of diabetic retinopathy. Ophthalmology 1995; 102:7-16.

7. Patel V, Rassam s, Newsom R, Wiek J and Kohner E. Retinal blood flow in diabetic retinopathy. Br Med J 1992; 305:678-683.

8. Moss SE, Klein R, Klein BEK. ten year incidence of visual loss in a diabetic poplation. Ophthalmology 1994; 101:1061-70.

9. Kohner EM. Aldington SJ, Nugent Z. Retinopathy at entry in the United Kingdom Prospective Diabetes Study (UKPDS) of Maturity Onset Diabetes. Diabetes 1987; 36 :(S1):42A.

10. Klen R, Klen BE, Moss Be, Moss SE, Davis Md. De Mets DJ. Prevalence and risk of Diabetic Retinopathy when age at diagnosis is less than 30 years and 30 years or more; Wisconsin epidemiological study of Diabetic Retinopathy. Arch Ophthalmol 1984; 102:520-532.

11. Klen R, Klen BEK, Moss Se, Retinopathy in young onest diabetic patients. Diab Care 1985; 8:311-315.

12. Mouton DP, Gill AJ. Prevalence on Diabetic Retinopathy and evaluation of risk factors: a review of 1005 diabetic clinic patients. S Afr Med J 1988; 74:399-402.

13. Kollarits CR, Kriess RD, Das A, Hall AM, Jordan EL and Donovan JR. Diabetic retinopathy and insulin therapy in a rural diabetic population. AM J Ophthalmol 1984;97:709714

14. Klein BEK, Moss SE and Klein R. Effect of pregnancy on progression of diabetic retinopathy. Diab Care 1990; 13:3440.

15. Thomas JM. Diabetic Retinopathy. New Eng J Md 1990; 322:978-983.

16. Definition, Diagnosis and Classification of Diabetes Mellitus and its complications. Report of a WHO consultation. Part 1: Diagnosis and classification of Diabetes Mellitus, WHO. Geneva 1999.

17. ADA report of definition diagnosis and classification of diabetes. Provisional Report of a WHO Consultation. Diabet Md 2000:15:539-553.

18. Tarbutton PN and Cunter Cr. Enzymatic determination of total cholesterol in serum. Clin Chem 1974;20:724

19. Richmond W. Preparation and properties of a cholesterol oxidase from Nocardia sp. And its application to the enzymatic assay of total cholesterol in serum. Clin Chem 1973; 19:1350.

20. Allain CA. Enzymatic determination of total serum cholesterol. Clin Chem 1974;20:470.
21. Fossati P and Prencipe L. Serum triglycerides determined colorimetrically with an enzyme that produces hydrogen peroxide. Clin Chem 1982; 28:2077.

22. Lopes-Virella M, Stone P, Ellis S and Colwell JA. Cholesterol determination in high density lipoproteins separated by three different methods. Clin Chem 1977; $23: 882$.

23. Friedewald WT. Estimation of serum low density lipoprotein. Clin Chem 1972;18:499.

24. Siperstein MD. Diabetic microangiopathy and the control of blood glucose. N Engl J Med 1983:309:1577-1579.

25. Khan AKA. Banik MG, Mahtab H. Malnutrition related Diabetes Mellitus in Bangladesh In: Rufkin H. Colwell JA. Taylor SL eds. Proceedings of 14th International Diabetes Federation Congress Washington DC: Diabetes 1991:944949.

26. Ballard DJ. Melton LJ, Dwyer MS. Risk factors for diabetic retinopathy. A population-based study in Rochester. Minnesota. Diabetes Care 1986; 9:334-342.

27. Frand RN. Hoffman WH, Podgor MJ, Retinopathy in juvenile onset type 1 diabetes of short duration. Diabetes 1982; 31:874-882.

28. Palmberg P. Smith M, Waltman S. The natural history of retinopathy in insulin dependent juvenile onset diabetes. Ophthalmology 1981; 88:613-18.

29. Ramsay RC. Goetz FG. Sutherland DER. Mauer SM. Robison LL, Canrrill HL. Progression of diabetic retinopathy after pancrease transplantation for insulin dependent Diabetes mellitus. N Eng JM 1988;318:208-213.

30. Klein R, Klein BEK, Moss SE. The Wisconsin Epidemiology Study of Diabetic Retinopathy II. Prevalence and risk of diabetic retinopathy when age at diagnosis is less than 30 years. Arch Ophthalmol 1984; 102:520-526.

31. Klein R, Klein BEK. Moss SE. The Wisconsin Epidemiology Study of Diabetic Retinopathy III. Prevalence and risk of diabetic retinopathy when age at diagnosis is less than 30 years. Arch Ophthalmol. $1984 ; 102: 527-532$

32. Guerci B, Meyer I, Sommer S, George JI. Ziegler O, Drouin $P$ and Angioiduprez. Sensitivity of Diabetic Retinopathy is linked to Lipoprotein(a) in type I diabetic patients. Diabet Motholism (Parts) 1999; 25:412-418.

33. Bishop YM. Feinberg SE. Holland PW. Discrete Multivariate Analysis: Theory and Practice Cambridge. Mass, MTT Press, 1975.

34. The Diabetes control and complications Trail Research Group. Color Photography VS Flureseem Angiography in the detection of diabetic retinopathy in the Diabetes control and complications trial. Arch Ophthalmol 1987; 105:13441351 